\section{Reviews of Undergraduate Departments: An External Reviewer's Perspective}

\author{
Paul Dawson \\ Oberlin College
}

Do you look forward to a trip to your dentist? Or a complete physical? If so, you probably don't need to read this.

However, if you're the sort who dreads (and usually forgets) their next check-up. read on..

Although it's typically a nondecision. your department may have to decide whether it will undertake an external review. Usually, the issue comes up when you and your colleagues are least inclined to pursue it: at the beginning of the semes ter. when you're just gearing up; during the middle of the semester. when you're facing the crunch of midterms: at the end of the semester, when you re trying hard to get everything done; at the beginning of the next semester, etc: On any of these occasions, you naturally wonder why you need any kind of review and probably find it quite tempting to put it off for another year (at least).

External reviews, I suspect, are easy to avoid or postpone. Although I lack comprehensive data on this point, I suspect that most colleges and universities have not routinized the review process by, for example, requiring every department to be reviewed every several years. Moreover, even when there are institutional routines, most departments, l imagine, can find compelling reasons for a postponement.

Since it's so easy to avoid one. why might you agree to an external review of your department?

There are three reasons, each with its own behavioral and institutional consequences and rationale: (1) You have no choice: (2) You want to protect your department: (3) You want to improve your department.
Reason 1. Passive Compliance. You ve postponed the review as long as you can; it's beginning to look as though you have something to hide. Since you are being gracious enough to put up with an external reviewer, hopefully the reviewer will be considerate enough not to try to make it a meaningful experience. Afterwards, your procedural claim to legitimacy reinforced. you can contınue doing what should be done.

Reason 2. Bunker Building, You're under attack. by those who don't know how hard you work or what good you do. since you know you're doing a good job. an external reviewer will help you defend what you do. legitimize your current claıms on resources, and resist admınistra. tive demands for change.

\section{Since it's 20 easy to avoid

one, why might you agree

to an external neview of

\section{your department?}

Reason 3. Growth. You want to do more: enrich and expand the curriculum; increase minority recruitment and retention: bring more academics and practitioners to campus: increase professional activity: etc. But, for any of these thıngs to happen, you need more resources. (Maybe an external reviewer can help reorder institutional priorities.)

All three reasons may enter into your decision to undertake an external review. In my experience, departments seem prompted initially by necessity: they have to do it. Once resigned. however, some of the members of the department come to see the review as an opportunity. either to defend the department or to improve it: others hope they will be able to comply more passively.

For whatever reason, let's assume you're now locked in.

What should you do? And what should you expect your external reviewer to do?

There are a number of possibilities in each phase of the review process: (1) Pre 
Review; (2) Review; and (3) Post-Review.

1. Pre-Review. To get ready for an external review, you might want to use the following checklist of things you should consider doing:

a. Reach agreement with the Powers That Be (PTB) on a procedure for selecting an external reviewer. Usually, PTB want to hear an independent vorce and, as a way of assuring them that you've found one, you might agree to select one from a list of recommended reviewers which you can get from the Association's Departmental Services Committee.

\section{You're under attack, by \\ those who don't know how \\ hard you work or what \\ sood you do.}

b. Get and follow the Association's recommended "Guidelines for Political Science Department Self-Study. " You'll need to allow some lead time for following these guidelines, since the most recent version runs 26 pages and calls for some information that you might not have readily available (e.g., enrollment trends, library acquisitions).

c. Line up your external reviewer: find out and begin compiling any additional information the reviewer might want.

d. Elicit concerns of PTB and departmental faculty; brainstorm questions: send these to the Reviewer.

e. Obtain written evaluations of courses and instructors from current students and possibly alumni.

2. Review. During the campus visit of the external reviewer, there are a number of things you might want to do:

a. Have all members of the Department meet informally with the Reviewer.

b. Have the Reviewer meet, individually, all on-campus members of the Department and appropriate administra- tors, plus any others the Reviewer may want to meet.

c. Have the Reviewer meet with some representative group of students and/or with the members of a Student Ma. jors' Committee, if you have one. (If you don't, you might want to form one, since the Reviewer probably will recommend it.) In addition, you might want to improve the Reviewer's access to students by hav. ing some serve as on-campus Guides.

d. Have the Reviewer meet with some faculty members from other depart. ments, of your, your Dean's, or the Re. viewer's, choosing.

e. At the conclusion of the visit. have the Reviewer make a preliminary oral report of findings to all members of the Department and make sure they get a chance to voice their initial reactions.

3. Post-Review. It's useful to think, ahead of time, about what you might ex. pect from an external review. Here are some possibilities:

a. You surely should expect to recelve a written report. Alternatively. you may want the Reviewer to return to campus to make an initial oral presenta. tion, before leaving a written report with you.

b. You should expect the written report to include all the sorts of informa. tion that one would find in any external review of any department, whether it be political science or physics, including assessments of:

- the breadth, depth, and struc. ture of the curriculum;

- the appropriateness of course reading and required course work;

\section{Departments are frompted initially by recessity.}

the accessibility of the curricu. lum to non-majors:

the richness of opportunities for upper level course work:

- the balance which major require. ments strike between specialization in a 
subfield and knowledge of the discipline;

- the availability of opportunities for training in quantitative analysis and for empirical research:

- the extent to which outside re. source persons, visiting political scientists and practitioners, enrich the curriculum and serve as role models;

- whether or not departmental faculty are spread too thinly, over too many different aspects of the discipline or over too many administrative responsibilities:

- the extent to which departmental faculty are active in scholarly pursuits. broadly defined:

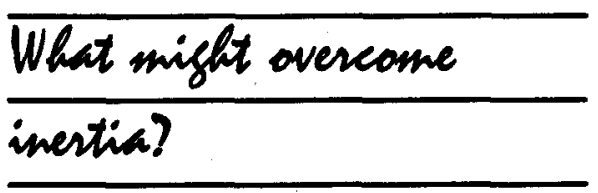

- the extent to which departmen. tal faculty are meeting the educational needs of all students. Including those variously disadvantaged:

- the farmess of faculty grading practices and the quality of faculty advising, as perceived by students;

- the adequacy of mechanisms by which the department elicits curricular concerns of students.

c. In addition. since yours is a report written by a political scientist, you should expect it to include all the sorts of information that one would find in any good political analysis of an institution. For example. I think a politically astute depart. mental review should answer the following questions about relationships among departmental faculty and between departmental faculty and those administrators who exercise some control over relevant resources:

(1) Are people aware of each other's goals, resources, and constraints?' other's goals?

(2) Do they accept. as valıd, each

(3) Are their fates interdependent? To what extent? Do they know, and accept, it?
(4) Are people engaging in "groupthink?" For example, do departmental faculty believe that key administrators are indifferent to departmental efforts? Antagonistic to departmental pursuits? Overly committed to an agenda which departmental faculty see as undesirable? Do key admınistrators adopt similarly adversarial belief systems? To what extent? Can such tendencies be reversed?

(5) is "privatization" under way? That is, do faculty act as though their private interest, as they define it, is unrelated to broader interests, as these are defined by the department or the college? To what extent? Is it possible to link private and public purposes in ways that energize faculty and rechannel commitment?

(6) Can administrators be en. couraged to invest in faculty as human capital?

(7) Do faculty invest in their own professional future? When asked to focus on It. do faculty members themselves think they over-respond to immediate demands, at the expense of their own professional development, activity, and moblity? If so, do they resent it? Does that resentment lower their morale and their commitment?

(8) Are faculty practicing what they teach? Most departmental faculty know something about politics - the ways. some more effective than others. people fight over values. the allocation of resources. power, etc. If departmental faculty have left the arena. can they reenter? If they have been behaving in ways which they now see as politically stupid. can they become more savvy?

(9) What might overcome inertia? If, upon review and reflection. departmen. tal faculty decide it is proper to change something. what can a department do to break out of the status quo? There are a rumber of possibilities. Sometimes, for example, an External Reviewer can alert departmental faculty to previously unknown shared faculty interests, previously undiscovered faculty allies, and even previously unfairly percelved administrators: all these are potential levers of change.

(10) What might mantain mo. 
mentum? Again there are a number of possibilities, although the ones l've found all require an increased flow to the depart. ment of the kinds of resources that are typically controlled by key administrators. The exploration of these possibilities. therefore, requires some initial good will, the willingness to negotiate, and some skill in forging pathways to joint gains. Some. tımes, an External Reviewer can elicit initial expressions of good will. facilitate negotiations, and add negotiation skills. ${ }^{2}$

In conclusion, I think that serving as an External Reviewer, if it's done well, is a lit. tle like trying to be a constructive theater critic for a show opening in Philadelphia. except you arrive during an ongoing drama of indeterminant length, and, once there, you have to figure out what has happened thus far, see where it's going, and, before it's over, try to pass on your advice to the actors so that they can try to make it a hit.

As the analogy suggests, it's hard to get the actors to listen. But, in my experience, they do listen and, I hope, sometimes find a new sense of allied, if not common, purpose - a sense which, if nurtured by good will and (even grudgingly given) mutual respect, can lead to an improved curriculum, a renewed sense of professional engagement, and a more vital institution.

\section{About the Author}

Paul Dawson is professor of government at Oberlin College.

\section{Notes}

1. As I have argued elsewhere. political institutions can be understood by identifying their goals, constraints, and resources, and by analyzing the ways in which they seek to create and transform resources. See Paul A. Dawson. American Government: Instilutions. Policies, and Pnlitics. Glenview, III.: Scott, Foresman, 1987.

2. Since the answers to these questions will affect the ability of a department to mprove itself, reviews of any and all departments. one might argue, should be carried out by political scientists, although I have yet to do so persuasively with any non-political scientist.

\section{The Long Voyage Home-Concluded}

\section{Donald Chisholm}

Ohio State University

In the first half of this essay on gaining an initial academic position, 1 I discussed de. veloping a standard placement file. finding out about job openings and the fit between oneself and a recruiting department, applying for the position, getting to the interview, and speaking with individual faculty and students. In this concluding seg. ment, I turn first to the most crucial part of any academic interview, the formal presentation of one's research to the assembled faculty of the recruiting department, and then finish with a discussion of what to expect if you receive a job offer and how to react if no such offer is forthcoming.

\section{The Formal Presentation}

The formal presentation of one's current research (usually the dissertation) is the single most important segment of any visit to a recruiting department. Here is where the department en masse has the opportunity to see you in the crucible. The typical format is a short (30-40 minutes) formal talk by the candidate followed by a question and answer period of similar length.

Because of the relatively short stay dur. ing any interview visit, recruiting departments tend to fill every available moment of the candidate's time. Eventually I grew savvy enough to ask for a half hour free prior to the formal talk, time to cool out and think a bit. Otherwise, one is likely to end up going directly from talking with a series of prospective colleagues to giving the presentation, followed by a question period, and, ultimately, brain death.

It is a well-kept professional secret that few members of a department will ever have read any of the written material a candidate is usually required to submit with his application. ${ }^{2}$ Candidates' curriculum vita's are often circulated, but specialization of knowledge by subfield, the heavy 